DEVELOPMENT OF SOLID

COLLECTION DIAGNOSTICS ON NIF

THROUGH BLAST SHIELD ANALYSIS

J. M. Gostic, D. A. Shaughnessy, P. M. Grant, I.

D. Hutcheon, L. A. Lewis, K. J. Moody

December 16, 2011

Nuclear Explosives Design Physics. Conference (NEDPC) at Los Alamos National Laboratory Los Alamos, NM, United States October 17, 2011 through October 21, 2011 
This document was prepared as an account of work sponsored by an agency of the United States government. Neither the United States government nor Lawrence Livermore National Security, LLC, nor any of their employees makes any warranty, expressed or implied, or assumes any legal liability or responsibility for the accuracy, completeness, or usefulness of any information, apparatus, product, or process disclosed, or represents that its use would not infringe privately owned rights. Reference herein to any specific commercial product, process, or service by trade name, trademark, manufacturer, or otherwise does not necessarily constitute or imply its endorsement, recommendation, or favoring by the United States government or Lawrence Livermore National Security, LLC. The views and opinions of authors expressed herein do not necessarily state or reflect those of the United States government or Lawrence Livermore National Security, LLC, and shall not be used for advertising or product endorsement purposes. 


\title{
DEVELOPMENT OF SOLID COLLECTION DIAGNOSTICS ON NIF THROUGH BLAST SHIELD ANALYSIS
}

Julie. M. Gostic, Dawn A. Shaughnessy, Patrick M. Grant, Ian D. Hutcheon, Laurence A. Lewis and Kenton J. Moody

Lawrence Livermore National Laboratory, 7000 East Ave.

Livermore, CA 94551 USA

\begin{abstract}
Radiochemical analysis of post-shot debris inside the National Ignition Facility (NIF) target chamber can help determine various diagnostic parameters associated with the implosion efficiency of the fusion capsule. This capability is limited by the amount of target isotope that can be loaded inside the capsule ablator without affecting performance and the collection efficiency of the capsule debris after implosion. Prior to designing a collection system, the chemical nature and distribution of the debris inside the chamber must be determined and analysis methods developed. The focus of our current work has been on determining the elemental composition and distribution of debris on various blast shields and witness plates that were exposed to the chamber during ignition shots that occurred in 2009. These passive collection plates were used to develop both non-destructive and chemical analysis techniques to determine debris composition and melt depth at various shot energy profiles. A summary of these data will be presented along with our current strategy for the 2011 campaign.
\end{abstract}

\section{Introduction}

Solid debris collection is essential for a variety of inertial confinement fusion experiments at NIF including capsule diagnostics $(\rho \mathrm{R})$, stockpile stewardship, and nuclear physics measurements. Successful measurement of non-volatile species formed in the high density plasma will depend on the amount of initial material added to the capsule and the ability to collect debris at concentrations greater than the detection limits of our current radiometric and mass analysis instruments. Simulations suggest that $\sim 10^{15}$ atoms of tracer material can be added to the inner most layer of the ablator shell of the capsule without affecting capsule performance. The neutron flux at peak burn will create of the order of $10^{6}$ atoms of reaction products which will be distributed throughout the target chamber. An ideal collection diagnostic should cover a wide area for enhanced collection efficiency; however, other critical diagnostics limit placement. Solid collection is also limited by the post-ignition chamber environment, i.e. heat, radiation and shock generated by the driver (laser), x-rays, target debris and shrapnel. The unconverted laser light and $x$-rays precede the activated radiochemical debris and ablate material from the surface of the 
collector, which may prevent adhesion of the target debris. The composition of the chamber environment and molten shrapnel also limit the tracers that can be placed in the capsule. As an example, $\mathrm{Cu}$ and $\mathrm{Si}$ are part of the target assembly; therefore, it would be impossible to separate an un-enriched $\mathrm{Cu} / \mathrm{Si}$ tracer from this debris.

The purpose of this work was to characterize post-ignition debris on passive collection plates that were designed to shield other diagnostics during Deuterium-Deuterium (DD) shots. The plates were characterized by non-destructive methods such as scanning electron microscopy (SEM), neutron activation analysis (NAA), wave length dispersive spectroscopy (WDS) and X-ray fluorescence spectroscopy (XRF). The results as they pertain to solid collection are provided.

\section{Experimental Results}

Several aluminum blast shields covering neutron activation diagnostics fielded 25 to $50 \mathrm{~cm}$ from Target Chamber Center (TCC) were selected for investigation. The shields were $4-6.5 \mathrm{~cm}$ in diameter and $1 \mathrm{~mm}$ thick. Shot energies ranged from approximately $50 \mathrm{~kJ}$ to $1 \mathrm{MJ}$, with $10^{9}$ neutron yield from either exploding pusher $(n=1)$ or indirect drive cryogenic D-D capsules with a $\mathrm{Au}$ hohlraum $(\mathrm{n}=10)$. Post-shot foils were visibly melted and discolored with significant differences between the shields fielded on the equator versus pole relative to TCC (Figure 1).

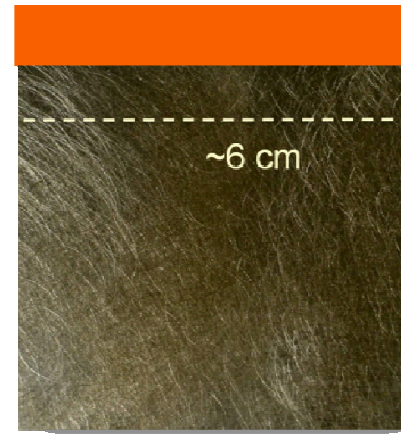

$46 \mathrm{~kJ}, 10^{9}$ neutrons

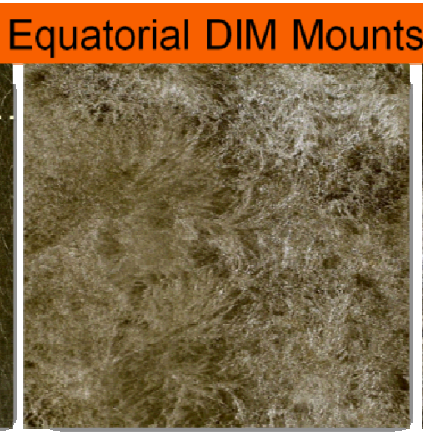

$689 \mathrm{~kJ}, 10^{9}$ neutrons

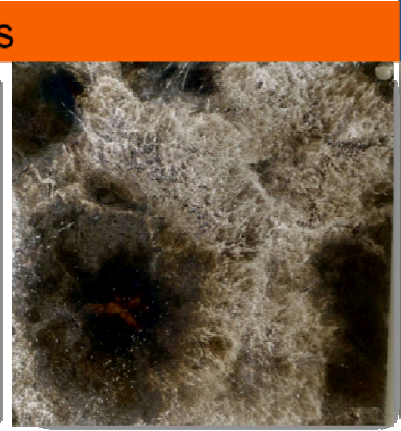

$836 \mathrm{~kJ}, 10^{9}$ neutrons

\section{Polar DIM Mount}

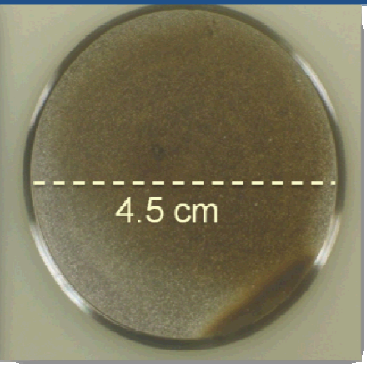

$567 \mathrm{~kJ}, 10^{10}$ neutrons

\section{Exploding Pusher, No hohlraum}

\section{Cryogenic D-D capsules with a Au hohlraum}

Figure 1. Examples of post-shot aluminum shields $(1 \mathrm{~mm}$ thick) fielded at the equator and pole of the target chamber. All shields were fielded $50 \mathrm{~cm}$ from TCC.

Surface analysis was completed using SEM coupled with energy dispersive spectroscopy (EDS) for elemental analysis. A representative image of the surface of the shields is provided (Figure 2). Surface features indicate that molten or partially molten and solid debris impacted the shield (splats and craters). The top layer of the Al shield is melted while the bulk material remains 
unaffected indicating that the localized surface temperature was greater than $660{ }^{\circ} \mathrm{C}$. The unevenness of the melt layer and the raised rounded features suggest material movement across the surface of the shield. Debris impact occurred while the surface was liquefied and after resolidification.

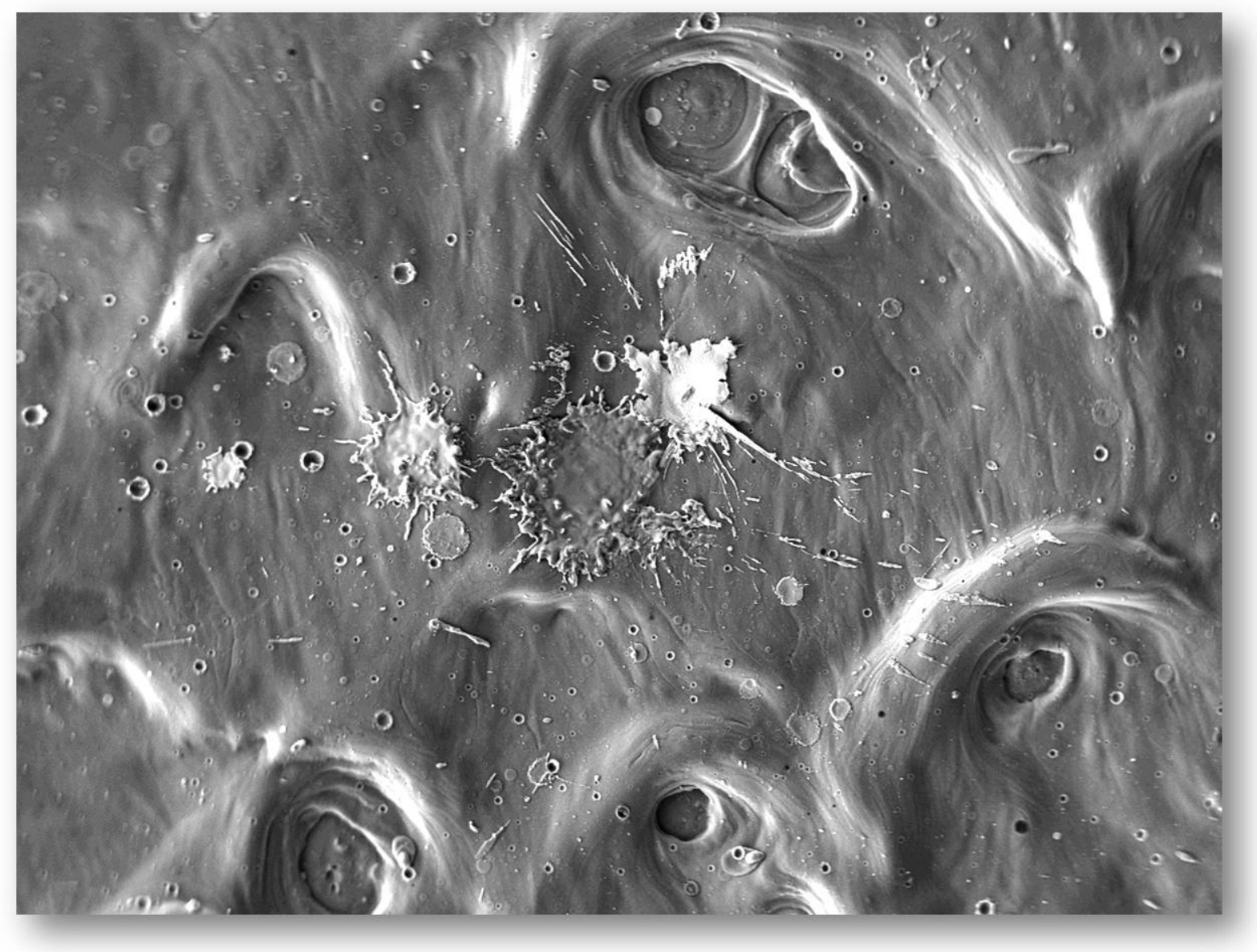

Figure 2. SEM image of a post-shot Al shield. The field of view is $300 \mu \mathrm{m}$.

Most of the elements identified by EDS could be traced to structural components inside the target chamber with the most prevalent being iron, chromium, and nickel (stainless steel). Additional debris from the target assembly was also identified including copper, indium, aluminum and silicon. The goal of this work is to collect debris from the target itself, however, these experiments were fielded with Ge-doped plastic capsules. The $\mathrm{C}-\mathrm{H}$ signal from the capsule cannot be distinguished from other carbon sources in the chamber and the Ge signal is below the limit of detection for surface analysis. Gold is unique to the hohlraum which houses the target capsule. Hohlraum debris was easily detected using surface analysis techniques and therefore became the focus for estimating collection efficiency on the Al shield. 
The solid angle subtended by the Al shield is $0.1-0.4 \%$ of the target chamber sphere depending on the distance from TCC. The gold hohlraum mass is $120 \mathrm{mg}$. Assuming a homogenous distribution and complete mixing, a maximum of $4-15 \mu \mathrm{g} \mathrm{Au} / \mathrm{cm}^{2} \mathrm{Al}$ was expected. From semiquantitative surface analysis techniques, less than 3\% (100-500 ng) of the Au was identified. The coupling of SEM/EDS provides elemental information about the first few $100 \mathrm{~nm}$ of the surface layer. The significant melting of the surface suggested that some of the debris may be embedded in melt layer. The Al shields were sectioned into roughly $15 \times 15 \mathrm{~mm}$ pieces and analyzed using neutron activation (NA) in April/May of 2011. The samples were irradiated at the USGS TRIGA reactor (Colorado) with a thermal neutron flux of $10^{12} \mathrm{n} / \mathrm{cm}^{2} \cdot \mathrm{sec}$ for 6 minutes along with a $\mathrm{Au}$ calibration standard. The $\mathrm{Au}$ content of the $\mathrm{Al}$ shield sub-pieces was quantitated by gamma spectrometry using the ${ }^{198} \mathrm{Au} \gamma$-line $(411.8 \mathrm{keV}$, with a radiative yield of $95.62 \%)$. The results of these experiments (Table 1) show that there is enhanced collection efficiency for Au on the Al shield.

Table 1. Gold distribution in the Al shield as determined by neutron activation analysis.

\begin{tabular}{|c|c|c|c|}
\hline Laser Energy (kJ) & $\begin{array}{c}\text { Distance to TCC } \\
(\mathrm{cm})\end{array}$ & $\begin{array}{c}\text { Measured } \\
\mu \mathrm{Au} \text { per } \mathrm{cm}^{2} \mathrm{Al}\end{array}$ & $\begin{array}{c}\text { Expected } \\
\mu \mathrm{Au} \text { per } \mathrm{cm}^{2} \mathrm{Al}\end{array}$ \\
\hline 516 & 50 & 20.14 & 4 \\
\hline 568 & 50 & 12.95 & 4 \\
\hline 574 & 50 & 21.15 & 4 \\
\hline 668 & 50 & 15.97 & 4 \\
\hline $\begin{array}{l}837 \\
567\end{array}$ & $\begin{array}{c}50 \\
50 \text { (Polar) }\end{array}$ & $\begin{array}{c}24.08 \\
0.05\end{array}$ & $\begin{array}{l}4 \\
4\end{array}$ \\
\hline 46 & 25 (no $A u$ ) & 0.03 & 0 \\
\hline 689 & 25 & 35.6 & 15 \\
\hline 729 & 25 & 26.71 & 15 \\
\hline 831 & 25 & 31.52 & 15 \\
\hline 836 & 25 & 25.94 & 15 \\
\hline
\end{tabular}

The shields were cross-sectioned to evaluate Au depth distribution. Electron microprobe analysis determined that most of the Au was embedded in the melt layer and was mainly associated with near surface and subsurface splats (Figure 3). The average weight percent of gold in the Al shield below the melt depth layer was $0.006 \pm 0.015$. Splats in the melt layer contained approximately 0.2 weight percent $\mathrm{Au}$. This data indicates that the gold impacted the liquid surface of the $\mathrm{Al}$ and remained trapped after re-solidification. 

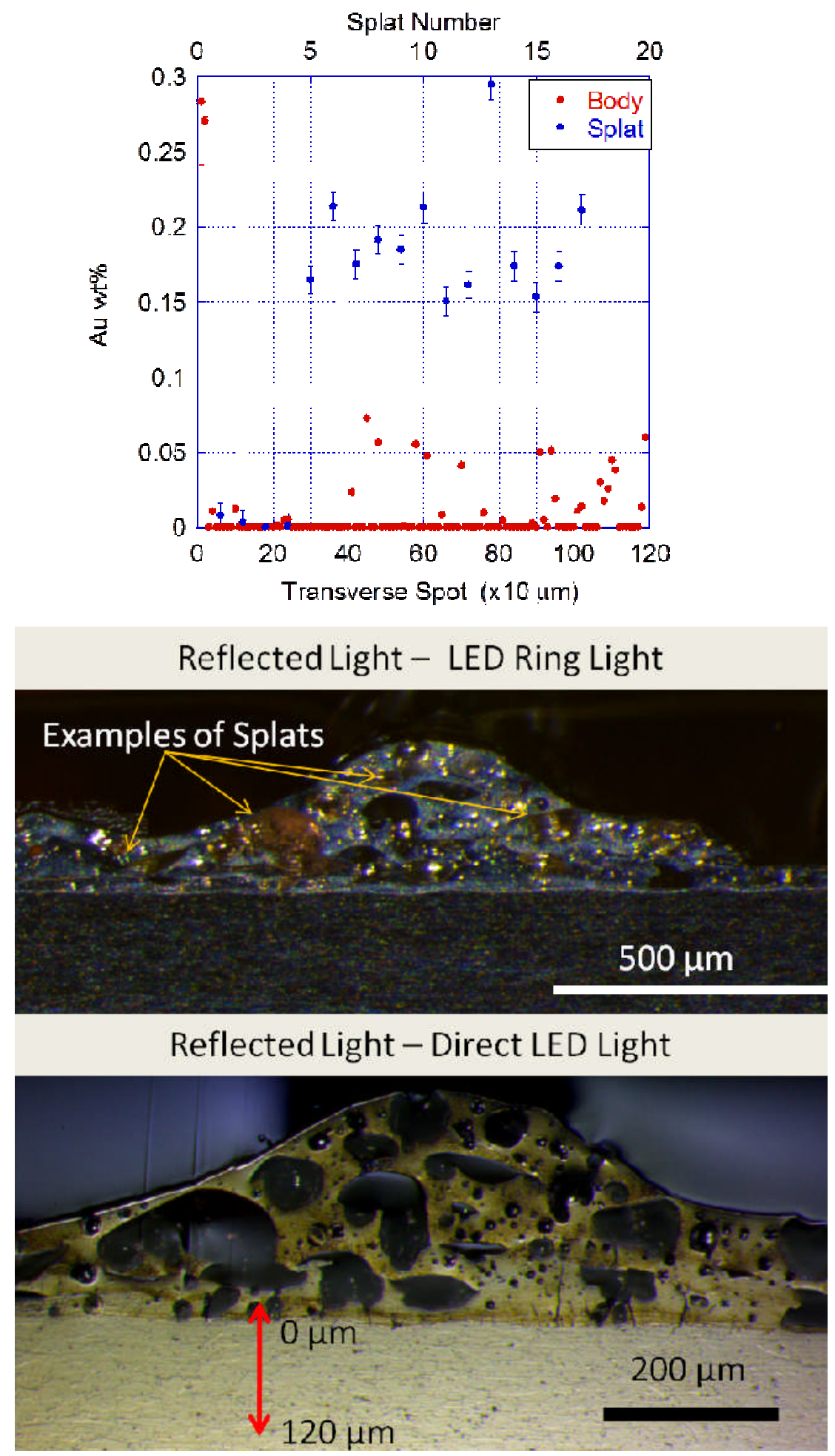

Figure 3. Electron microprobe analysis of the cross-sectioned Al shields through the melt layer and bulk material. The transverse spot data corresponds to the arrows in the lower optical image. 


\section{Conclusions}

Though Au has been our primary focus for these initial samples, Ge analysis will help to quantify capsule debris collection. The Al shields contained traces of $\mathrm{Mn}$, which prevented analysis of Ge after NA. New metals have been selected and fielded (May 2011) for passive collections that do not contain impurities that will affect Ge analysis and have higher melting points than Al.

\section{Acknowledgements}

The authors would like to thank Rick Ryerson (LLNL) for providing the electron microprobe data and Uwe Greife, Bob Larson and Marty Hudson for the neutron activation analysis. This work performed under the auspices of the U.S. Department of Energy by Lawrence Livermore National Laboratory under Contract DE-AC52-07NA27344. 